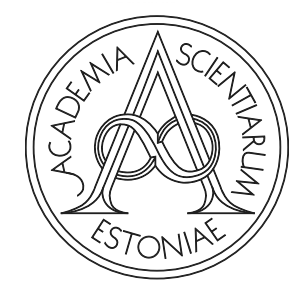

Proceedings of the Estonian Academy of Sciences, $2021,70,4 \mathrm{~S}, 333-340$

https://doi.org/10.3176/proc.2021.4S.04

OPTOMETRY

Available online at www.eap.ee/proceedings

\title{
Accommodative response in various design soft contact lens wearers
}

\author{
Evita Kassaliete*, Anastasija Gordeja, Karola Panke, Anete Petrova and Gunta Krumina \\ Department of Optometry and Vision Science, Faculty of Physics, Mathematics and Optometry, University of Latvia, Jelgavas iela 1, \\ LV-1004, Riga, Latvia
}

Received 22 October 2020, accepted 9 March 2021, available online 23 September 2021

(C) 2021 Authors. This is an Open Access article distributed under the terms and conditions of the Creative Commons AttributionNonCommercial 4.0 International License (http://creativecommons.org/licenses/by-nc/4.0/).

\begin{abstract}
The progression of myopia in young adults due to inadequate accommodation is currently one of the global research challenges. Studies have demonstrated that multifocal contact lenses have a different effect on accommodative response. The aim of this study was to assess the accommodative lag using various design multifocal contact lenses at different working distances. The study was conducted on 10 emmetropic subjects aged 22-28 years. An open-field autorefractor PowerRef 3 was used to assess the response of eye accommodation to stimuli placed at a distance of $25 \mathrm{~cm}$ and $40 \mathrm{~cm}$ for subjects wearing monofocal and multifocal contact lenses. To determine the effectiveness of contact lens design for accommodative lag compensation, the results of the accommodative lag with and without contact lenses were compared. The measured accommodative lag for stimuli at $40 \mathrm{~cm}$ was $1.05 \pm 0.11 \mathrm{D}$ and for stimuli at $25 \mathrm{~cm} 1.53 \pm 0.11 \mathrm{D}$. Regarding the effect of multifocal contact lenses, it was determined that the near vision power zone in the centre of the lens reduces the accommodative lag, while the respective distance vision power zone does not produce a statistically significant change. The near power zone in the centre of the multifocal contact lens effectively affects the accommodative lag by reducing accommodation inaccuracy as effectively as spherical contact lenses with positive power. The addition design for multifocal lenses (Med or Hi) does not significantly affect the accommodative lag. The results of centre-distance multifocal contact lenses depend on the strength of the addition used.
\end{abstract}

Key words: accommodative lag, multifocal contact lenses, near addition, myopia control.

\section{INTRODUCTION}

Reducing the progression of myopia is a topical issue in today's society and in the research community. The effect on the myopization process resulting from the type of correction such as bifocal spectacle lenses, peripheral defocus lenses, orthokeratology lenses, multifocal lenses and pharmaceutical agents is actively studied (Madrid-Costa et al. 2011; Walline et al. 2011; Remón et al. 2020). The use of contact lenses in children and in young adult population reduces peripheral hypermetropic defocus on the retina, which occurs in the case of spectacle correction. Moreover, the near addition used in multifocal contact lenses allows for the patient to maintain good visual

\footnotetext{
${ }^{*}$ Corresponding author, evita.kassaliete@lu.lv
}

resolution without defocus at the retinal periphery and reduce accommodation demand during near work (computer, reading). There are two main types of simultaneous image contact lens designs: concentric multifocal contact lenses and aspheric multifocal contact lenses. Manufacturers offer different profiles of multifocal contact lenses with near or distance power zones in the centre of the lens. Previous studies of multifocal contact lenses have clearly demonstrated that the results highly depend on the type of contact lenses used, methodology, patient's physiological pupil size and the quality of lens centration (Pérez-Prados et al. 2017; Zhu et al. 2019; Remón et al. 2020).

Eye accommodation is an automatic adjustment of the lens curvature, resulting in a change in the focal length of the eye by bringing images of objects from various 
distances into focus on the retina. The increase in the optical strength of the eye is a complex combination of sensory, neuromuscular and biophysical processes. This process ensures that a patient is able to see clearly both at distance and near (Benjamin 2006). However, 8\% of children and young adults have accommodation dysfunctions, which is regarded as one aspect of myopization process in children (Pettersson et al. 2011). Accommodation errors which occur in the event of the accommodative lag place the focus behind the fixation point, leading thus to accommodative insufficiency. Conversely, an error that occurs in the case of the lead of accommodation places the focus before the fixation point and results in accommodative excess, e.g., over-focusing of close visual objects (Schor 1999).

The magnitude of the accommodative lag determines the power of near addition and is influenced by the following factors: patient's age (Anderson et al. 2009), fixation distance of accommodative stimulus, size of accommodative stimulus, refractive state (McBrien and Millodot 1986), and interaction between accommodation and vergence. An optometrist who prescribes multifocal contact lenses for young adults should understand how and to what extent the specific contact lens profile affects the patient's accommodation. Therefore, the aim of this study was to determine the accommodative lag using various design multifocal contact lenses at working distances of $40 \mathrm{~cm}$ and $25 \mathrm{~cm}$ of the accommodative stimulus and to identify the most effective profile of the multifocal contact lens. The enabling objectives were set as follows. Firstly, to determine the size of the accommodative lag for the accommodative stimuli of $2.5 \mathrm{D}$ and $4 \mathrm{D}$. Secondly, to evaluate and compare the effect of multifocal contact lens design on the accommodative lag. It was hypothesized that different profiles of multifocal contact lenses have an equal effect on the accommodative lag. Thirdly, to compare the effectiveness of additive in spherical and multifocal contact lenses. It was hypothesized that multifocal contact lenses reduce the accommodative lag equally to the spherical type of contact lenses.

\section{MATERIALS AND METHODS}

\subsection{Participants}

Ten emmetropic subjects $(M=24 \pm 1$ year, range $22-28)$ participated in the study, where the spherical equivalent of objective refraction did not exceed $\pm 0.50 \mathrm{D}$. The selected subjects had no vision pathologies and had a distance visual acuity of at least 1.0 decimal units. The participants verbally confirmed that they were not taking prescription medications.

\subsection{Instruments}

The dynamic accommodative response to the specific stimulus was measured with an open-field autorefractor PowerRef 3. The refractions were measured in vertical meridian in monocular condition. The working range for the device PowerRef 3 is the following: spherical range $+5.00 /-7.00 \mathrm{D}$ with $0.01 \mathrm{D}$ step, with pupil size under photopic condition $(4.0-8.0 \mathrm{~mm})$ with $0.1 \mathrm{~mm}$ step, sampling period of $0.02 \mathrm{~s}(50 \mathrm{~Hz}$ sampling rate), optical pathway length of $1 \mathrm{~m}( \pm 5 \mathrm{~cm})$. The device consists of a camera and a system comprising a chin rest, a mirror system and a rail with a camera adapter (Plusoptix Inc. 2018). The measurements were recorded with the program Standard 10s within ten seconds after covering the nondominant eye, on average 500 values per measurement.

\subsection{Study design}

The study was performed in accordance with the Declaration of Helsinki. The study had ethics committee approval and a written informed consent form was signed by the participants. All the participants gave their informed consent prior to examination. For each participant we performed measurements with six different types of contact lenses on the sensory dominant eye. Table 1 presents the list of contact lenses that were used in the experiment. The type of contact lenses and the sequence of measurements were randomized between participants to avoid methodological errors.

Initially, the measurement was performed without contact lenses at a distance of $6 \mathrm{~m}$ to include the effect of baseline refractive error and only then the first contact lens was inserted. The centration of the contact lenses was assessed five minutes after insertion. Following the successful contact lens fitting, we continued with measurements at distances of $6 \mathrm{~m}, 40 \mathrm{~cm}$ and $25 \mathrm{~cm}$. For each participant the completion of the experiment took 2 hours on average. The theoretical accommodation demand for $25 \mathrm{~cm}$ and $40 \mathrm{~cm}$ was $4.0 \mathrm{D}$ and $2.5 \mathrm{D}$, respectively. The accommodative lag was calculated as the difference between the amount of theoretical accommodation stimulus demand and the measured accommodative response (Madrid-Costa et al. 2011):

$$
\text { Accommodative lag }=\frac{1}{d}-(A R P R-P P R),
$$

where $d$ is the stimulus distance (m), ARPR represents the objective accommodative response measured with PowerRef 3 at near (D), PPR denotes the baseline objective refraction at far measured with PowerRef 3 before the beginning of the task (D). 
Table 1. The list of the used contact lenses with different Add design, power and type

\begin{tabular}{|c|c|c|c|c|c|c|c|}
\hline Lens type & Title & Manufacturer & Diameter & Base curve & Power & Add & Design \\
\hline AOMed & Air Optix Aqua Multifocal & Alcon & 14.2 & 8.6 & $\mathrm{pl}$ & 2.0 & $\mathrm{~N}$ lens \\
\hline $\mathrm{AOHi}$ & Air Optix Aqua Multifocal & Alcon & 14.2 & 8.6 & $\mathrm{pl}$ & 2.5 & $\mathrm{~N}$ lens \\
\hline BF1.5 & Biofinity Multifocal & Cooper Vision & 14.0 & 8.6 & $\mathrm{pl}$ & 1.5 & D lens \\
\hline $\mathrm{BF} 2.0$ & Biofinity Multifocal & Cooper Vision & 14.0 & 8.6 & $\mathrm{pl}$ & 2.0 & D lens \\
\hline Sph. +1.5 & Biofinity & Cooper Vision & 14.0 & 8.6 & Sph. $+1.5 \mathrm{D}$ & & \\
\hline Sph. +2.5 & Biofinity & Cooper Vision & 14.0 & 8.6 & Sph.+2.5 D & & \\
\hline
\end{tabular}

$\mathrm{N}$ lens - power zone for near in the centre of the lens, $\mathrm{D}$ lens - power zone for distance in the centre of the lens.

\subsection{Data analysis}

Data analysis was carried out using descriptive statistics in Microsoft Excel and Prism GraphPad. For the testing of normality of the measured values, Kolmogorov-Smirnov normality test was applied. The lag of accommodation in AOMed at the fixation distance of $40 \mathrm{~cm}$ did not show normal distribution, while others showed normal distribution within the sample. The data with normal distribution was analysed with parametric tests. For the comparison of means between two groups (e.g., accommodative lag at $40 \mathrm{~cm}$ and accommodative lag at $25 \mathrm{~cm}$ responses), the dependent samples $t$-test for means was implemented. To analyse the difference between the means of more than two groups, the two-way ANOVA test along with Tukey's multiple comparisons test with a single pooled variance was applied. The threshold and confidence level corresponds to 0.05 (95\% confidence interval). Due to the limited sample size $(n=10)$, the results with and without correction were also correlated by non-parametric tests, which shows similar statistic results in comparing variances.

\section{RESULTS AND DISCUSSION}

The average baseline accommodative lag that represents the condition without contact lenses was significantly higher for $4.0 \mathrm{D}$ accommodative demand $(25 \mathrm{~cm}$ distance, $M=1.53 \mathrm{D}, S D=0.40 \mathrm{D})$ compared to $2.5 \mathrm{D}$ accommodative demand (40 cm distance, $M=1.05 \mathrm{D}, S D=0.33 \mathrm{D}$ ) (dependent samples $t$-test, $t(9)=5.98, S E M=0.08, p<$ 0.001). Our results are in accordance with the findings reported by Tarrant et al. (2008) in showing that the accommodative lag increases with increasing accommodative stimuli.

We compared further the increase in the accommodative lag depending on the accommodative stimulus (AS2.5D via AS4.0D) for 3 types of contact lenses. The dependent samples $t$-test for the accommodative lag was taken between each correction type at two distances. The increase in the accommodative lag was not significantly different from the spherical lens type of $1.5 \mathrm{D}$, it seems that this power interacts in the similar way with the accommodative lag for near work at $25 \mathrm{~cm}$ or $40 \mathrm{~cm}$. But the spherical lens type of $2.5 \mathrm{D}$ shows a significant difference in $2.5 \mathrm{D}$ and $4.0 \mathrm{D}$ stimuli. The clear explanation is that the power $2.5 \mathrm{D}$ for the stimulus at $40 \mathrm{~cm}$ totally relaxes accommodation and we do not observe accommodative response there because of no interaction on it. On the other hand, at a distance of $25 \mathrm{~cm}$, it is still necessary to have the power $1.5 \mathrm{D}$ for accommodation. The results show that Air Optix Aqua multifocal contact lenses (near power zone in the centre of the lens) interact in the similar way to the accommodative lag in changing near work distance. When Biofinity Multifocal contact lenses (BF 1.5; BF 2.0) were compared, we obtained a statistically significant change in the accommodative lag for different near work distances. This statistical analysis proved that the correction type and near work distance are important factors for evaluating the accommodative lag (see Table 2).

To understand the effect of addition and the previously mentioned factors on the accommodative lag, we used a two-way ANOVA analysis. We operated with three factors: correction type (4 levels: Air Optix, Biofinity, spherical and without contact lens), near work distance (2 levels: $25 \mathrm{~cm}$ and $40 \mathrm{~cm}$ ) and addition (2 levels: high and medium). Does the correction type have a significant effect? As each correction type has two power levels (high and medium), but the control group (without contact lens) did not have such a division, then we compared the total effect of the correction for each level of addition separately. For the medium level of addition, the accommodative lag values were submitted to a two-way ANOVA with two near work distances and four correction types. The main effect of distance was significant, $F(1,72)=$ $12.19, M S=2.69, p<.001, \eta^{2}=0.17$, suggesting that the test accommodative lag at a closer fixation distance 
Table 2. Accommodative lag median and mean values with standard deviation $(S D)$ in diopters for contact lenses of different types and power profiles, as well as dependent samples' $t$-test $p$-values at $40 \mathrm{~cm}$ and $25 \mathrm{~cm}$

\begin{tabular}{lc|c|c|c|c|c}
\hline Lens type & AS & \multicolumn{5}{c}{ Accommodative lag (D) } \\
\cline { 3 - 7 } & & Median & Mean & $S D$ & $p$ & Paired $t$-test \\
\hline AOMed & $2.5 \mathrm{D}$ & 0.89 & 0.82 & 0.41 & 0.048 & $t(9)=2.29$ SEM $=0.13$ \\
& $4.0 \mathrm{D}$ & 1.02 & 1.12 & 0.61 & & \\
AOHi & $2.5 \mathrm{D}$ & 0.81 & 0.77 & 0.36 & 0.048 & $t(9)=2.29$ SEM $=0.18$ \\
& $4.0 \mathrm{D}$ & 1.15 & 1.20 & 0.47 & & \\
BF1.5 & $2.5 \mathrm{D}$ & 1.32 & 1.32 & 0.29 & 0.013 & $t(9)=3.11$ SEM $=0.13$ \\
& $4.0 \mathrm{D}$ & 1.66 & 1.72 & 0.51 & & \\
BF2.0 & $2.5 \mathrm{D}$ & 0.60 & 0.80 & 0.47 & 0.002 & $t(9)=4.35$ SEM $=0.15$ \\
& $4.0 \mathrm{D}$ & 1.44 & 1.44 & 0.60 & & \\
$1.5 \mathrm{sph}$ & $2.5 \mathrm{D}$ & 0.85 & 0.89 & 0.47 & 0.19 & $t(9)=1.56$ SEM $=0.15$ \\
& $4.0 \mathrm{D}$ & 1.17 & 1.18 & 0.62 & & \\
$2.5 \mathrm{sph}$ & $2.5 \mathrm{D}$ & 0.45 & 0.58 & 0.40 & 0.008 & $t(9)=3.39$ SEM $=0.15$
\end{tabular}

$\mathrm{AS}(2.5 \mathrm{D})$ - accommodative stimulus at $40 \mathrm{~cm}, \mathrm{AS}(4.0 \mathrm{D})$ - accommodative stimulus at $25 \mathrm{~cm}$.

$(25 \mathrm{~cm})$ was greater than at $40 \mathrm{~cm}$. The main effect of the correction type was more significant, $F(3,72)=5.74$, $M S=1.27, p<.01, \eta^{2}=0.24$, suggesting that the accommodative lag varies with the type of correction. The interaction was not significant, $F(3,72)=0.19, M S=0.04$, $p=.9$. For the higher level of addition, the main effect of distance was more significant, $F(1,72)=24.96, M S$ $=5.17, p<.001, \eta^{2}=0.35$, suggesting that the test accommodative lag at a closer fixation distance $(25 \mathrm{~cm})$ was greater than at $40 \mathrm{~cm}$. The main effect of correction type was less significant, $F(3,72)=3.67, M S=0.76$, $p<.05, \eta^{2}=0.15$, suggesting that the accommodative lag varies due to the correction type. The interaction was not significant, $F(3,72)=0.20, M S=0.04, p=.9$. Hence, for both addition levels (high and medium) the two-way ANOVA results indicate that the near work distance and the type of correction are important factors. Moreover, the near work distance and the type of correction do not interact, which means that the correction type effect does not depend on the near work distance. The distance effect is stronger for higher addition whereas the correction type effect is stronger for the medium level of addition. The results in Table 1 account for the absence of the interaction effect by demonstrating that the distance effect across the treatment group is about the same when looking at the average value. According to medians after some treatment, there is a greater difference in accommodative lag values.

As the effect of the correction type is statistically significant, the post-hoc tests (Tukey's multiple comparisons test) were performed to determine how effectively the lens type reduces the accommodative lag compared to the (control) state without contact lens. Table 3 introduces mean differences in the accommodative lag

Table 3. Comparison of accommodative lag differences without correction and with the specified correction type of contact lenses, fixating the stimulus at $40 \mathrm{~cm}$ and $25 \mathrm{~cm}$

\begin{tabular}{llc|c|cr|r}
\hline \multicolumn{2}{c}{ High level of addition } & \multicolumn{2}{c}{ Medium level of addition } \\
\hline \multirow{2}{*}{ AS(2.5D) } & \multicolumn{2}{c|}{ Mean diff. (D) } & \multicolumn{1}{c}{$p$} & \multicolumn{2}{c}{ Mean diff. (D) } & $p$ \\
& Control vs AOHi & 0.27 & 0.54 & Control vs AOMed & 0.23 & 0.70 \\
& Control vs BF2.0 & 0.25 & 0.60 & Control vs BF1.5 & -0.27 & 0.59 \\
& Control vs + 2.5 D sph & 0.47 & 0.11 & Control vs + 1.5 D sph & 0.16 & 0.87 \\
AS(4.0D) & Control vs AOHi & 0.33 & 0.36 & Control vs AOMed & 0.42 & 0.20 \\
& Control vs BF2.0 & 0.10 & 0.96 & Control vs BF1.5 & -0.19 & 0.81 \\
& Control vs + 2.5 D sph & 0.45 & 0.13 & Control vs + 1.5 D sph & 0.35 & 0.35
\end{tabular}

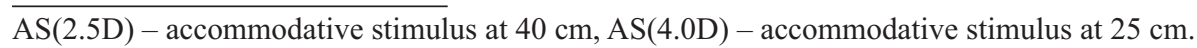


with different addition levels for two near work distances (40 $\mathrm{cm}$ and $25 \mathrm{~cm}$ ) and $p$-values.

The results show that most lens types reduce the accommodative lag compared to the control condition (without lens), but not significantly (the confidence level is less than 95\%). However, Biofinity 1.5 multifocal contact lenses interact differently from the other types. In this case, the distance profile in the centre of the lens does not reduce the lag but rather activates the accommodation, e.g., a lead of accommodation was estimated. As optometrists we calculate how effectively different correction types interact with the accommodative lag. Figure 1 shows the change in the percentage of the accommodative lag versus the accommodative demand (in Fig. 1a for the stimulus at $40 \mathrm{~cm}$ and in Fig. $1 \mathrm{~b}$ for the stimulus at $25 \mathrm{~cm}$ ).

Figure 1 indicates that the multifocal centre-distance contact lenses do not reduce the accommodative lag but increase the accommodative lead, which is supported by Plainis et al. (2013), who estimated that for Biofinity (centre-distance power zone) contact lenses the near additions are substantially lower than the manufacturer's values. Under photopic conditions or for strong near triad responses when pupil size is smaller, the actual effect of near addition might be insignificant. However, it is true that the effect of near addition might be enhanced for larger pupils as well as by small amounts of lens decentration. The introduction of greater amounts of aberration in the attempt to increase the effective addition would be expected to be accompanied by substantial losses in visual acuity at distance. In turn, the power of near addition shows a different action on the accommodation. Our hypothesis that the different profiles of multifocal contact lenses have an equal effect on the accommodative lag was rejected. The change in the power zone of

(a)

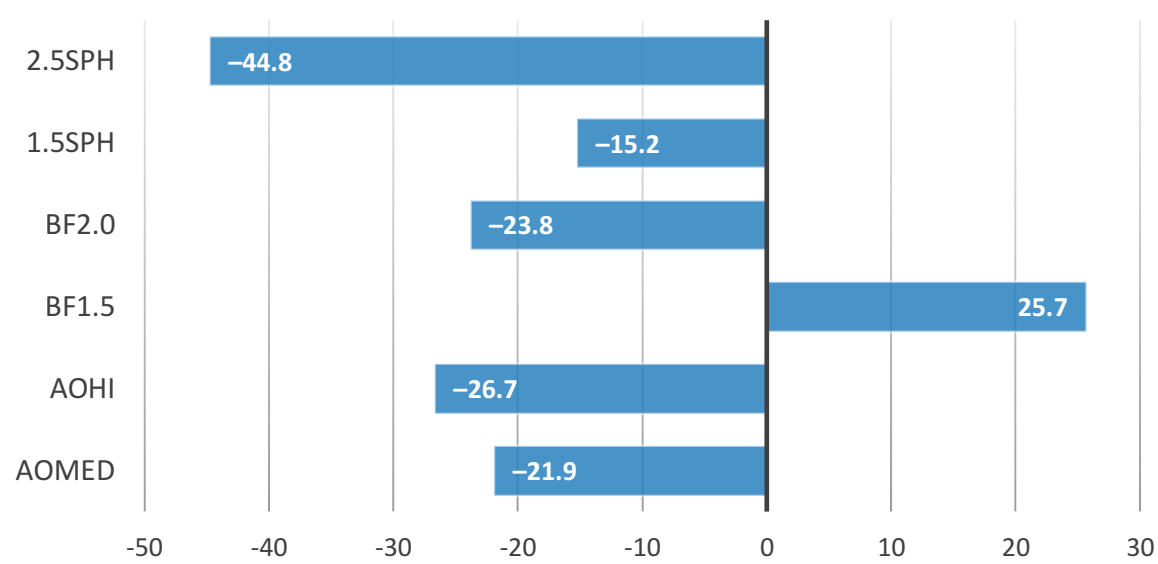

Accommodative lag changes (\%)

(b)
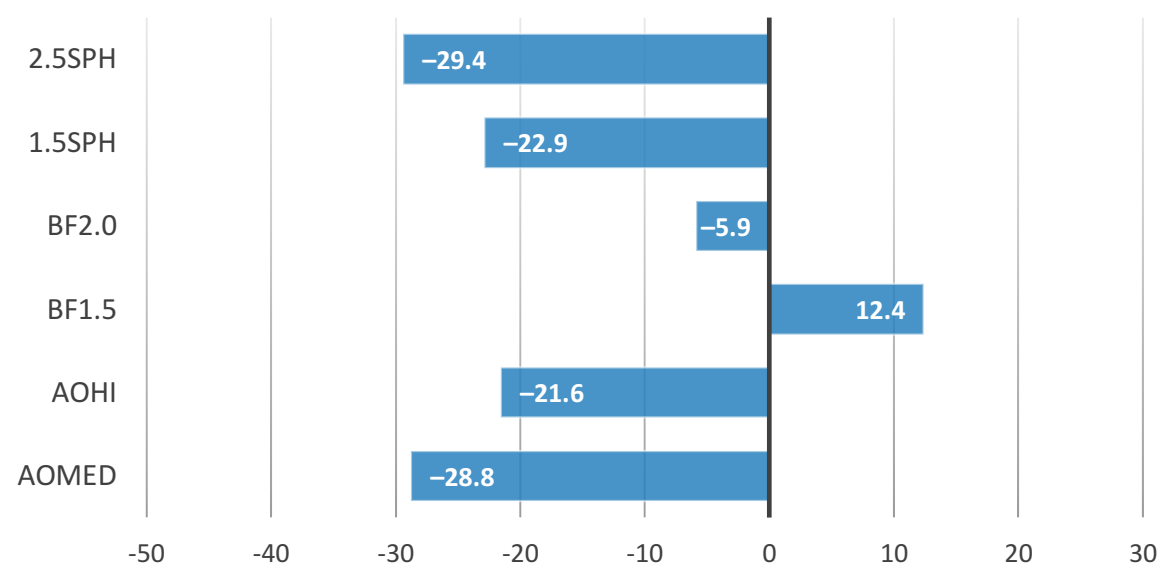

Accommodative lag changes (\%)

Fig. 1. Accommodative lag changes in percentage (\%) for different treatments in contact correction (a) at $40 \mathrm{~cm}$ distance and (b) at $25 \mathrm{~cm}$ distance. 
the multifocal contact lens depends on the level of the addition as well as on the power profile of the manufactured contact lens. The accommodative response, in its own turn, depends not only on the design and power profile of the multifocal contact lens, but also on the size of the physiological pupil diameter (Plainis et al. 2013).

The research aimed at determining whether the level of multifocal contact lenses addition (high and medium) has a similar effect on the accommodative lag compared to spherical contact lenses for near work, and for that purpose the total effects of the lens type for two near work distances were compared. For $40 \mathrm{~cm}(\boldsymbol{A S} 2.5 \mathrm{D})$, the accommodative lag results were submitted to a two-way ANOVA with two levels of the addition and three types of contact lenses. The main effect on the level of the addition was significant, $F(1,54)=7.65, M S=1.25, p<.01$, $\eta^{2}=0.14$, suggesting that the test accommodative lag reduces with increasing addition power. The main effect of the lens type was also significant, $F(2,54)=3.53$, $M S=0.58, p<.05, \eta^{2}=0.13$, suggesting that the accommodative lag varies with the type of contact lenses. The interaction was not significant, $F(2,54)=1.73, M S=0.28$, $p=.19$. For $25 \mathrm{~cm}$ (AS4.0D), the effect of the addition level was not significant, $F(1,54)=0.48, M S=0.15$, $p=.49$, suggesting that for $25 \mathrm{~cm}$ distance two addition levels provide similar reduction in the accommodative lag. We detected that the lens type significantly changes how addition interferes with the accommodative lag, $F(2,54)=3.98, M S=1.26, p<.05, \eta^{2}=0.15$. The interaction was not significant, $F(2,54)=0.54, M S=0.17$, $p=.59$, which shows no interaction between the level of addition and the lens type. The accommodative lag differs from manufacturer lens profiles and power zone distribution. As the effect of the correction type is statistically significant, post-hoc tests (Tukey's multiple comparisons test) comparing brands among themselves were performed by considering each distance separately. The results of post-hoc tests are presented in Table 4.
At the high level of addition at both near work distances, significant differences across different manufacturers were not determined, while the multifocal centre-near contact lenses, e.g., Air Optix, produced an effect on the accommodative lag similar to the spherical type of contact lenses.

At the medium level of addition, the Air Optix (centrenear power zone) contact lenses produced an effect on the accommodative lag that was more similar to the spherical type of contact lenses, while Biofinity multifocal (centredistance power zone) contact lenses differed the most in the accommodative lag when comparing with the spherical type of contact lenses. The small sample size of participants did not allow to prove this as significant. Air Optix vs Biofinity multifocal lenses produce statistically different effects, due to different power profiles and lens designs. We have established that multifocal centre-near contact lenses reduce the accommodative lag at both distances more effectively and more precisely than spherical contact lenses. Therefore, the hypothesis stipulating that multifocal contact lenses reduce the accommodative lag similarly to spherical additions is relevant only for high addition multifocal lenses at both fixation distances and for medium addition multifocal centre-near lenses. As the effect of the addition level was not significant for $25 \mathrm{~cm}$ and the accommodative lag differences compared to spherical contact lenses are the smallest for both working distances, we suggest medium addition centre-near multifocal contact lenses for clinical use and for reducing the accommodative lag.

\section{CONCLUSIONS}

The results indicate that the accommodative lag can be reduced with different correction types in contact lenses. The most important factor is the near work distance that represents accommodative demand, followed next by the correction type and then by addition power. The correction

Table 4. Accommodative lag comparison between different types of contact lenses with high and medium addition for near work distances $(25 \mathrm{~cm}$ and $40 \mathrm{~cm})$

\begin{tabular}{llc|c|crrr}
\hline & \multicolumn{3}{c}{ Accommodative stimulus at 25 cm } & \multicolumn{2}{c}{ Accommodative stimulus at 40 cm } \\
\hline \multirow{2}{*}{ High power } & Mean diff. (D) & $p$ & \multicolumn{2}{c}{ Mean diff. (D) } & $p$ \\
& Air Optix vs Biofinity & -0.24 & 0.62 & Air Optix vs Biofinity & -0.02 & 0.99 \\
& Spherical vs Air Optix & -0.12 & 0.88 & Spherical vs Air Optix & -0.20 & 0.53 \\
& Spherical vs Biofinity & -0.36 & 0.34 & Spherical vs Biofinity & -0.22 & 0.47 \\
Medium power & Air Optix vs Biofinity & -0.60 & $0.05^{*}$ & Air Optix vs Biofinity & -0.50 & $0.02^{*}$ \\
& Spherical vs Air Optix & 0.07 & 0.96 & Spherical vs Air Optix & 0.07 & 0.93 \\
& Spherical vs Biofinity & -0.54 & 0.09 & Spherical vs Biofinity & -0.43 & 0.06
\end{tabular}

For analysis we used the two-way ANOVA test along with Tukey's multiple comparisons test. 
type effect does not depend on the near work distance and the distance effect is stronger than the correction type effect or addition power. The results demonstrate that centre-near contact lenses work effectively and could be used to reduce the accommodative lag. Multifocal contact lenses with a centre-distance $(\mathrm{BF})$ power profile displayed different results depending on the size of the additive used.

We cannot really prove all the findings statistically due to the small sample size but tendences were observed. The complicated and lengthy procedure precludes the assessment of a large number of participants. Our small sample size does not affect the generalizability of our results. It is possible to use the two-sample $t$-test sample size calculation - if the sample size were increased to 20 , these $p$-values would be reduced from 0.20 to 0.048 (assuming that the sample means and standard deviations remained the same). For analysis we estimated the difference between the groups that was observed in our sample effect size $\left(\eta^{2}\right)$ to detect a difference with a specified power, as a smaller effect size will require a larger sample size. Contact lenses with such a profile directly reduce peripheral defocus, which theoretically reduces the long-term progression of myopia (Berntsen and Kramer 2013; Lam et al. 2014; Wolffsohn et al. 2016; Zhu et al. 2019). The scholars maintain that the reduction in the progression of myopia results from such factors as pupil size, aberrations, accommodation and centration of contact lenses. Berntsen et al. (2007) investigated the correlation between the accommodative lag and juvenileonset myopia progression. The magnitude of the accommodative lag was not associated with the annual change in refractive error, but the child's age had a significant association with the annual progression of myopia. The researchers concluded that the accommodative lag was not significantly associated with myopia progression. These data suggest that greater amounts of hyperopic retinal blur due to near activities do not drive juvenile-onset myopia progression. This study did not consider which of the factors - peripheral retinal defocus or retinal blur due to near activities - is more important in the progression of myopia, but it suggests that in the case of binocular dysfunctions based on the increased accommodative lag, multifocal contact lenses with a centre-near design can be used to reduce the accommodative lag.

\section{ACKNOWLEDGEMENTS}

This study was conducted within the framework of Project No. KC-PI-2020/10 "Development of vision screening and training equipment" and supported by Project No. Y5-AZ77ZF-N-100. The publication costs of this article were partially covered by the Estonian Academy of Sciences.

\section{REFERENCES}

Anderson, H. A., Glasser, A., Stuebing, K. K. and Manny, R. E. 2009. Minus lens stimulated accommodative lag as a function of age. Optom. Vis. Sci., 86(6), 685-694. https://doi.org/10.1097/OPX.0b013e3181a7294f

Benjamin, W. J. 2006. Borish's Clinical Refraction. Butterworth-Heinemann, Oxford.

Berntsen, D. A. and Kramer, C. E. 2013. Peripheral defocus with spherical and multifocal soft contact lenses. Optom. Vis. Sci., 90(11), 1215-1224. https://doi.org/10.1097/OPX.0000000 000000066

Berntsen, D., Sinnott, L., Mutti, D. and Zadnik, K. 2007. Accommodative lag is not related to myopia progression. American Academy of Optometry. Program No. 070049. https://www.aaopt.org/detail/knowledge-base-article/accom modative-lag-not-related-myopia-progression

Madrid-Costa, D., Ruiz-Alcocer, J., Radhakrishnan, H., Ferrer-Blasco, T. and Montés-Micó, R. 2011. Changes in accommodative responses with multifocal contact lenses: a pilot study. Optom. Vis. Sci., 88(11), 1309-1316.

McBrien, N. A. and Millodot M. 1986. The effect of refractive error on the accommodative response gradient. Ophthalmic Physiol. Opt., 6(2), 145-149.

Lam, C. S. Y., Tang, W. C., Tse, D. Y.-Y., Tang, Y. Y. and To, C. H. 2014. Defocus incorporated soft contact (DISC) lens slows myopia progression in Hong Kong Chinese schoolchildren: a 2-year randomised clinical trial. Br. J. Ophthalmol., 98(1), 40-45 https://doi.org/10.1136/bjophthalmol-2013-303914

Pérez-Prados, R., Pinero, D. P., Pérez-Cambrodí, R. J. and Madrid-Costa, D. 2017. Soft multifocal simultaneous image contact lenses: a review. Clin. Exp. Optom., 100(2), 107127. https://doi.org/10.1111/cxo.12488

Pettersson, A. L., Ramsay, M. W., Lundström, L., Rosén, R., Nilsson, M., Unsbo, P. et al. 2011. Accommodation in young adults wearing aspheric multifocal soft contact lenses. Vis. Sci. Ophthalmic Opt., 58(19-20), 1804-1808.

Plainis, S., Atchison, D. A. and Charman, W. N. 2013. Power profiles of multifocal contact lenses and their interpretation. Optom. Vis. Sci., 90(10), 1066-1077.

Plusoptix Inc. 2018. https:/plusoptix.com/products/accommodationreasearch/powerref-3; https://plusoptix.com/fileadmin/Downloads/ Products/Research product models/PowerRef-3 PR09/Plusoptix PR09_User_manual_Version-5022_english.pdf

Remón, L., Pérez-Merino, P., Macedo-de-Araújo, R. J., Amorim-de-Sousa, A. I. and González-Méijome, J. M. 2020. Bifocal and multifocal contact lenses for presbyopia and myopia control. J. Ophthalmol., 8067657. https://doi.org/ 10.1155/2020/8067657

Schor, C. 1999. The influence of interactions between accommodation and convergence on the lag of accommodation. Ophthalmic Physiol. Opt., 19(2), 134-150.

Tarrant, J., Severson, H. and Wildsoet, C. F. 2008. Accommodation in emmetropic and myopic young adults wearing bifocal soft contact lenses. Ophthalmic Physiol. Opt., 28(1), 62-72.

Walline, J. J., Lindsley, K., Vedula, S. S., Cotter, S. A., Mutti, D. O. and Twelker, J. D. 2011. Interventions to slow progression of myopia in children. Cochrane Database Syst. Rev., 12, CD 004916. https://doi.org/10.1002/14651858.CD004916.pub3 
Wolffsohn, J. S., Calossi, A., Cho, P., Gifford, K., Jones, L., Li, M. et al. 2016. Global trends in myopia management attitudes and strategies in clinical practice. Cont. Lens Anterior Eye, 39(2), 106-116. https://doi.org/10.1016/j.clae.2016.02.005
Zhu, Q., Liu, Y., Tighe, S., Zhu, Y., Su, X., Lu, F. et al. 2019. Retardation of myopia progression by multifocal soft contact lenses. Int. J. Medical Sci., 16(2), 198-202. https://doi.org/10.7150/ijms.30118

\title{
Akommodatsiooni reaktsioon erineva disainiga pehmete kontaktläätsede kandjatel
}

\author{
Evita Kassaliete, Anastasija Gordeja, Karola Panke, Anete Petrova ja Gunta Krumina
}

Müoopia progresseerumine noortel täiskasvanutel ebatäpse akommodatsiooni tulemusena on optomeetrias üheks oluliseks uurimisteemaks. Varasemad uuringud on näidanud, et multifokaalsetel kontaktläätsedel on akommodatsioonile erinev efekt. Uuringu eesmärk oli mõõta akommodatsiooni mahajäämust, kasutades erineva disainiga pehmeid kontaktläätsi erinevatelt nägemiskaugustelt. Uuring viidi läbi kümne emmetroobi hulgas vanuses 22-28 aastat. Silmade akommodatsiooni reaktsiooni uuriti autorefraktomeetri PowerRef 3 abil. Stiimulid asetati 25 ja $40 \mathrm{~cm}$ kaugusele katseisikutest, kes kandsid mono- ning multifokaalseid kontaktläätsi. Et teada saada kontaktläätsede disaini efektiivsus akommodatsiooni mahajäämusele, võrreldi omavahel akommodatsiooni mahajäämust ilma ja koos kontaktläätsedega. Akommodatsiooni mahajäämus stiimulile $40 \mathrm{~cm}$ kauguselt oli 1,05 $\pm 0,11 \mathrm{D}$ ja stiimulile $25 \mathrm{~cm}$ kauguselt 1,53 $\pm 0,11 \mathrm{D}$. Kui hinnati multifokaalsete kontaktläätsede akommodatsiooni mahajäämust, leiti, et läätsed lähivaatamise alaga läätse keskosas vähendasid akommodatsiooni mahajäämust, samas kui kaugelevaatamise tugevus läätse keskel olulist muutust esile ei kutsunud. Järgnevalt uuriti, kas optometristid kasutasid lisaks prillidele multifokaalseid kontaktläätsi, saamaks sarnast efekti akommodatsiooni mahajäämusele. Multifokaalne lääts lähitsooniga läätse keskel mõjutas efektiivselt akommodatsiooni mahajäämust, vähendades akommodatsiooni ebatäpsust sarnaselt plusstugevusega sfäärilistele kontaktläätsedele. Lähilisa suurus multifokaalsetes läätsedes (Med või Hi) ei mõjutanud akommodatsiooni mahajäämust. Läätse keskosas asuva kaugelevaatamise alaga multifokaalsete läätsede korral sõltusid tulemused lähilisa tugevusest. 